\title{
The Role of Product Lifecycle Management Systems in Organizational Innovation
}

\author{
Hamzeh K. Bani Milhim, Xiaoguang Deng, Andrea Schiffauerova, and Yong Zeng* \\ Concordia Institute for Information Systems Engineering, \\ Faculty of Engineering and Computer Science, Concordia University, \\ 1455 Maisonneuve West, Montreal, Quebec, Canada, H3G 1M8 \\ yong . zeng@concordia.ca
}

\begin{abstract}
Innovation is a critical ingredient of today's organizations. Innovativeness helps organizations to maintain their success and position in the market. Numerous research studies examine the factors that impact successful organizational innovation, for example organizational learning capability, organizational structure, etc. Product Lifecycle Management (PLM) systems have been widely implemented to support organizational innovation as well. In this paper, we will discuss the role of PLM systems in fostering the organizational innovation success. Moreover, future trends based on the current PLM systems that would provide further support to the organizational innovativeness will be explained.
\end{abstract}

Keywords: organizational innovation, PLM systems, fostering innovation.

\section{Introduction}

Innovation is considered as the major engine of organizational success. Organizations need to adopt and develop new products and services, and to improve their processes in order to maintain their goals such as profit, growth and continuous development. In addition, they are constantly required to increase their effectiveness and efficiency towards accomplishing their business goals. In fact, the trend in modern organizations nowadays is to include a continuous effort to enhance their innovativeness in their goals and strategies, because without being innovative organizations simply cannot survive in the competitive market. In order to meet the requirements of innovative organizations, it is thus essential to develop new technologies and business models, supporting the organizational innovation. One of such models, Product Lifecycle Management (PLM) system, has been developed in the last decade as a technology to manage the product development from idea generation stage to the end of life of a product. There are many benefits organizations can gain through implementing PLM systems such as increasing innovativeness, reducing product development cost, enhancing collaboration in the development process, etc. [1,2].

\footnotetext{
* Corresponding author.
} 
More recently, PLM systems have been adopted by many organizations due to their capabilities related to the product development in its lifecycle. PLM includes many powerful functionalities that support product development throughout the different lifecycle phases such as data vault management, release and change management, configuration management, project management, etc. [3]. In fact, PLM objectives are to support the main development processes of organizations including micro and macro processes, where micro processes involve in the early stages of product development such as product design, process design and production system design, while the macro processes include production planning, production scheduling and production control, and the group of service operations such as marketing, procurement, sales, distribution, after sales services, and quality and maintenance operations [4]. Organizations can foster their innovation capability in various ways; for instance, supporting various organizational behavior factors can have strong positive contribution to innovation, or adopting and implementing supporting technologies such as PLM technologies can facilitate and streamline operations for better innovation. PLM systems can be considered as one of the most promising technologies in supporting the organizational innovation. In the PLM stream of literature the researchers argue that PLM fosters innovation in organizations. Nevertheless, few of them discussed the application of PLM systems in organizational innovation.

Many research studies have been carried out to address the role of organizational technologies in supporting innovation. For example, Sharma [5] discussed the integration of collaboration, product development and innovation using PLM as a technology framework in order to capture the benefits that can be gained by organizations out of such integration. Moreover, Swink [6] examined the role of PLM systems in overcoming the barriers of collaborative innovation. In his paper, he addressed the necessity of integrating product innovation and supply chain process innovation, and of enhancing collaboration, easy knowledge access and awareness. In addition, Awazu et al. [7]studied the role of information-communication technologies (ICT) in supporting innovation in terms of facilitating collaboration, easiness of reaching, recording and reviewing ideas from internal and external sources such as suppliers, vendors, customers and employees. The authors argued in their paper that "ICTs enable the entire innovation process, form idea generation and development to experimenting, and finally to commercialization of ideas". Finally, Cascini [8] discussed the importance of integrating the Computer Aided Innovation [9] tools with PLM systems to support organizational innovation.

The purpose of this paper is to examine the role of PLM systems in supporting organizational innovation by highlighting the features of PLM and discussing their benefits in various stages of organizational innovation. The rest of the paper is organized as follows: the next section briefly discusses the PLM concepts, benefits and scope, while in section 3, the organizational innovation, concepts, importance of innovation to organizations, and factors that support organizational innovation are explained. In section 4, we examine how PLM systems can support the organizational innovation process throughout the different stages of innovation, and outline future trends in PLM systems towards supporting and enhancing innovation process. Section 5 concludes and suggests the directions for future research. 


\section{Product Lifecycle Management Systems}

Product Lifecycle Management (PLM) is a holistic business approach which emerged in late 1990's. It is a concept that represents the strategy of integrated management which addresses the requirements of the development and management of the complete set of product-related data throughout the lifecycle across the extended enterprise. PLM provides the business approach to best manage and use the intellectual capital (IC) that includes the product definition, product history and the best practices of enterprises [10]. PLM systems emerged from the evolution of engineering technologies in the last two decades from Computer Aided Design and Computer Aided Manufacturing (CAD/CAM), Computer Aided Engineering (CAE) and Product Data Management (PDM) [11]. According to Lee et al. [12], PLM systems emerged from two roots: enterprise management, which involves for instance Materials Requirement Planning (MRP), Enterprise Resources Planning (ERP) and eXtended Relationship Management (XRM), and product information management, this allows the integration of the legacy systems of enterprises in order to support product development throughout the lifecycle phases.

CIMdata, which is a PLM consulting company, defined PLM as "a strategic business approach that applies a consistent set of business solutions in support of the collaborative creation, management, dissemination, and use of product definition information across the extended enterprise from concept to end of life - integrating people, processes, business systems, and information" [13]. The most generic acceptable representation of the lifecycle phases is shown in Figure 1. PLM systems focus on the extended product, which can be represented according to Cao et al. [14] in three layers model including the center layer which deals with the functionalities of the product, the tangible product layer which deals with the packaging of the core functions of the product, and intangible product layer which deals with product services.

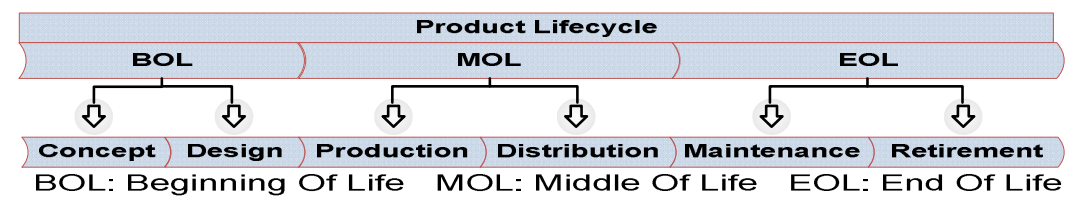

Fig. 1. Product lifecycle phases

Organizations have been recently adopting the PLM systems, because there are numerous benefits that can be gained from their implementation. Ming et al. [15] classified the benefits of PLM implementation into customer and company benefits: Customer benefits include high quality of products and services, and an increase in customer satisfaction, whereas company benefits involve mass customization, reduction in project failure rates, delivery of more innovative products in shorter time, reduction of product realization time, effective management and utilization of enterprise intellectual capital, effective communication and collaboration among different inter- and intra-enterprises at dispersed locations, as well as minimization of 
manufacturing costs [16].Moreover, society benefits such as less industrial and commercial waste throughout the lifecycle stages, and more awareness of environmental issues have been highlighted by various scholars [17].

PLM concepts cover wide range of technologies and techniques that aim to support product development process, in terms of product data management throughout all the lifecycle phases, collaborative product development, enterprise resources integration, or intra- and inter-organizational communication. According to Fasoli et al. [18], the core of the PLM approach is an integrated data and process meta model managed by a database management system. The same authors classified the available PLM methods and tools into three major groups: information management, process management and application integration methods. Information management includes identifying, structuring, classifying, modeling, retrieving, and sharing information, while process management involves methods for structuring, planning and controlling processes. Applications integration methods deal with defining and managing interfaces between PLM systems and different authoring applications.

\section{Organizational Innovation}

Organizational behavior is defined as a field that examines the behavior of these individuals within organizational setting as well as the structure and behavior organizations themselves [19]. Studying the organizational behavior is considered essential in order to enhance our understanding of the complexities of organizations. The field of the organizational behavior covers the body of knowledge derived from studying those behavioral actions and attitudes. In fact, organizational behavior can be understood through its key elements which are people, technology, structure and environment [20]. Furthermore, the organizational innovation can be analyzed and understood in the context of organizational behavior.

In the literature, the innovation process is defined as an application of new ideas to the products, processes or other aspects of the activities of an organization that lead to increased value [21]. Innovation can have many faces, for instance it can be incremental or radical innovation, process or product innovation, and it also can be technological or administrative innovation. Furthermore, in its generic form in organizational settings the organizational innovation process is defined as either referring to an adoption of work or production technologies new to the organization, or to the changes in organizational structure or managerial practices, but also it can refer to the market introduction of the fruits of internal or external research and development activities [22].

Realization of an innovation needs to go through the innovation stages. The stages of the innovation process as defined by Cumming [23] are the idea generation, the successful development of that idea and then its successful implementation However, Greenhalg et al. [21] divided the innovation process into research and development, commercialization and diffusion. The idea generation stage is usually based on the innovative ideas, which can be either a result of in-house research effort or they can be gathered from outside the organization. During the idea development stage the idea is transferred from the conceptual form to the applicable form, and then, finally, it can 
be commercialized. The innovation is diffused internally and $\backslash$ or externally for wider use of costumers in order for the organization to be able to gain the benefits and reap the profit.

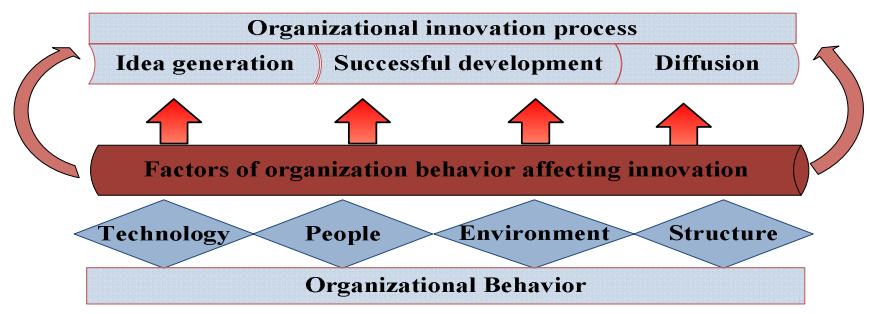

Fig. 2. Organizational behavior in supporting innovation

Research in innovation is truly rich in terms of addressing the factors that can contribute positively to successful organizational innovation. Organizational factors can be understood in the context of organizational behavior through the main elements of organizational behavior. People-related factors discussed in the literature are for instance transformational leadership [27], adoptability culture [28], open mindedness [29], and individual innovative behavior [30]. Structure-related factors are for example formalization [31], centralization [31] and organizational complexity [32], while the examples of environment-related factors include low uncertainty avoidance and power distance [33]. Finally, technology-related factors involve organizational learning capability [34], and individual and organizational creativity mechanisms [35]. These factors can play a vital role in increasing the organizational innovativeness. Moreover, organizations are searching for other possible ways how to enhance their innovative capabilities through adopting and implementing various technologies and solutions. One of those important technologies is PLM.

\section{$4 \quad$ PLM Role in Fostering Organizational Innovation}

PLM involves managing the whole process of product development from the initial idea generation to the retirement stage, and it brings all the expertise, resources and technologies from supply chain networks together in order to support the development process. Consequently, the core objectives of PLM systems is to provide the technological tools to manage the products' information, and to promote collaboration process of the organizational supply chain network [36]. In fact, one of the key business factors that allow organizations to obtain a competitive advantage is innovation and management of product development throughout all of its lifecycle phases [37]. Indeed, PLM is one of the major technologies that foster the organizational innovation. PLM systems include the required features and technologies for product development, ranging from data management, interoperability and resources integration, support collaboration to knowledge management capabilities. The role of PLM systems in supporting organizational innovation can be understood through 
understanding its role in supporting the stages of innovation process discussed earlier. Moreover, we intend to highlight PLM features that play important roles in enhancing the success of the organizational innovation in order to reflect the importance of PLM system to the innovation process.

A lot of attention has been paid to the early stage of innovation. This basically includes the idea generation, which most people relate to the organizational creativity as a source of ideas for innovation. Extensive research has been done on individual and organizational innovation. On the other hand, in a generic understanding of innovation, the idea source can be also found outside the organization.. In fact, PLM systems provide rich sources of new ideas that can be developed or adopted based on the repository of data about customers, markets, vendors, etc. According to the theory of "economics of ideas" developed by Romer [38]in 1993, making people knowledgeable brings innovation and continued ability to create products and services of the highest quality which will eventually lead to the economic growth [39].

Basically, innovation processes comprise multidisciplinary activities that require disperse teams combining expertise and experience in various fields [40]. PLM systems play an important role in supporting the collaborative capabilities of the various product stakeholders. PLM systems enhance open communication and the interaction among various people experienced in different fields, who can easily share and combine their knowledge and resources of product development [41].Such a multiuser and multidisciplinary process can truly foster idea generation. For instance, the Customer Relationship Management (CRM) feature of PLM systems allows organizations to review the behavior of their customers and to increase awareness about their needs. In addition, PLM systems allow the free flow of ideas, experience and knowledge which can provide a rich source of new innovative ideas in terms of outsourced ideas or stimulation of new ideas [42]. Another important factor is organization learning capability, which has been known to contribute to successful organizational innovation [43]. Organizational learning supports creativity, enhances organizational knowledge, stimulates ideas generation and enhances development processes [44]. PLM strongly supports the organizational learning capability in terms of the collaboration, resources integration, and communication features.

The second stage of innovation process is the successful development of ideas and realization of ideas in an applicable form. PLM systems allow organizations to take advantage of the expertise and the volume available beyond the boundaries of their organizations. Groups of specialized capabilities can be assembled together, while combining internal expertise and size with the capability of integrated resources such as computer aided tools for testing, simulation and validation, in order to develop new innovations. In addition, traceability feature of PLM systems allows great visibility of product changes to the product stakeholders within the organizational supply chain network. Such visibility and traceability of product changes, together with the ability of various stakeholders to collaborate on the idea development, increase the success rate of the development process. Other important elements of organizational innovation include the management support of innovative culture, a customer/market focus, and high level of internal and external communication [45]. PLM systems enhance the dialogue and participative decision making, which in turn boosts the management support of innovation process and increases learning capabilities of process stakeholders. 


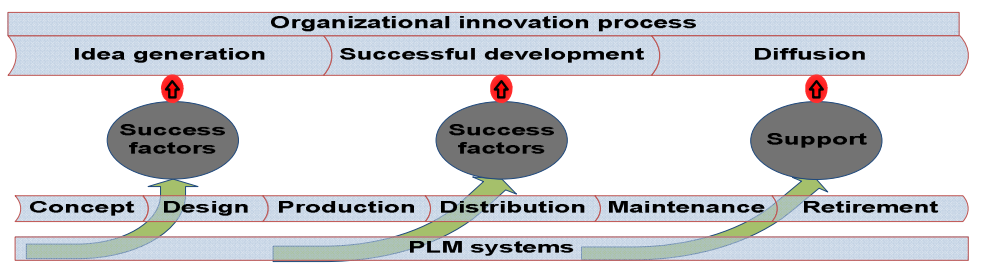

Fig. 3. Relationship between organizational innovation process and PLM systems

Furthermore, the organizational process alignment also plays an important role in organizational innovation [28]. PLM systems supply the processes and the platform for organizational structure, strategic planning and information technology, hence facilitating successful innovation [28]. Moreover, PLM systems play a vital role in creating and enhancing an open and rich climate for innovation, through the support of risk taking and the encouragement to do new things and to consider various opinions. In addition, collaboration support and resource integration features of PLM systems allow for the best use of the specialized human resources in organizations. In fact, PLM systems support item-focused task assignment which allows the taskexpertise matching for best results possible.

For the innovation to be successful, it should be diffused from within the organization to external stakeholders in the supply chain network. Here, the benefits from the use of PLM systems can be achieved in a wide range. PLM systems allow not only the circulation of information, but also the reinforcement of trust, both in terms of credit and relations between organizations. Build-up of social capital through social interactions, reinforcement of trust and sharing of organizational knowledge will also foster innovation process and diffusion of new innovations [46]. Furthermore, the fact that PLM brings all stakeholders to the same platform to work in collaboration on product development makes all the involved parties aware of latest developments and new innovations, which enhances the diffusion of the new innovative ideas further. In addition, the visibility of changes and modifications of the new ideas to all the stakeholders facilitate their diffusion as well. Besides, the fact that PLM systems provide strong connections with customers makes the commercialization of new ideas throughout the customer networks easier and more straightforward.

In fact, many research and PLM vendors are aware of the importance of PLM technology to organizational development (illustrated in Fig.3). Many future directions and trends proposed by various authors need to be considered and adopted by the current PLM systems. The suggested trends in PLM systems include enhancing environmental awareness of organizations, improving integrations of organizational resources, supporting collaborative products development and fostering organizational innovations. Nowadays, the market offers several tools to improve designer creativity and problem solving capabilities with a systematic approach [8]. For instance, there are tends suggest integrating Computer Aided Inventing (CAI) tools [9] to PLM systems in order to enhance the creativity and the idea generation in the early stages of innovation. Such CAI tools include the theory of inventive problem solving (TRIZ), Quality Function Deployment (QFD), axiomatic design, six sigma and others that can 
introduce topological optimization systems as a bridge capable of generating optimal solutions [8]. In addition, PLM systems need to fully integrate approaches and roles to support the continuous improvement of organizations such as lean manufacturing and thinking, Total Quality Management (TQM), etc. [47]. However, current PLM systems still do not fully support the integration of organizations' resources in terms of interoperability of available legacy systems and knowledge management features. In fact, this negatively affects the best use of resources and the effective information sharing during the product development processes. Interoperability and systems integration need to be further enhanced to enable the optimal use of organizational knowledge by the product development process stakeholders.

\section{$5 \quad$ Conclusion and Future Development}

This paper discussed the impact of PLM systems on the organizational innovation process. Based on a critical literature review analysis, we can conclude that an effective PLM system can significantly enhance the success of organization innovation capability. This conclusion will be validated through a survey studies designed to measure the impact of PLM on organizational innovation in our upcoming research. Furthermore, case studies represent how PLM systems enhance organizational innovation need to be discussed to validate our claims regarding the importance of PLM role in innovation.

\section{References}

1. Dutta, D., Wolowicz, J.P.: An introduction to product lifecycle management, PLM (2005)

2. Liu, W., Zeng, Y.: Conceptual Modeling of Design Chain Management towards Product Lifecycle Management. Global Perspective for Competitive Enterprise, Economy and Ecology, 137-148 (2009)

3. Terzi, S.: Elements of product lifecycle management: Definitions, open issues and reference models (2005)

4. Garetti, M., et al.: Organisational change and knowledge management in PLM implementation. International Journal of Product Lifecycle Management 1(1), 43-51 (2005)

5. Sharma, A.: Collaborative product innovation: integrating elements of CPI via PLM framework. Computer-Aided Design 37(13), 1425-1434 (2005)

6. Swink, M.: Building collaborative innovation capability. Research-technology Management 49(2), 37-47 (2006)

7. Awazu, Y., et al.: Informationcommunication technologies open up innovation. ResearchTechnology Management 52(1), 51-58 (2009)

8. Cascini, G.: State-of-the-art and trends of computer-aided innovation tools. Building the Information Society, pp. 461-470 (2004)

9. Cai, S., Li, Y., Li, T., Deng, R.H., Yao, H.: Achieving high security and efficiency in RFID-tagged supply chains. International Journal of Applied Cryptography 2(1), 3-12 (2010)

10. Limited, D.: Understanding Product Lifecycle Management, Cambridge, CB3 0QQ, United Kingdom (2002) 
11. Georgalas, N., et al.: Agile product lifecycle management for service delivery frameworks: history, architecture and tools. BT Technology Journal 26(2), 65-86 (2009)

12. Lee, S.G., et al.: Product lifecycle management in aviation maintenance, repair and overhaul. Computers in industry 59(2-3), 296-303 (2008)

13. CIMdata, Product lifecycle management: empowering the future of business (2002)

14. Cao, H., et al.: RFID in product lifecycle management: a case in the automotive industry. International Journal of Computer Integrated Manufacturing 22(7), 616-637 (2009)

15. Ming, H.X.G., Lu, W.F., Zhu, C.F.: Technology challenges for product lifecycle management. STR/04/058/SP (2004)

16. Lockamy III, A., McCormack, K.: Analysing risks in supply networks to facilitate outsourcing decisions. International Journal of Production Research 48(2), 593-611 (2010)

17. Ming, X.G., et al.: Collaborative Product Lifecycle Management in Virtual Enterprise Ecosystem Business Challenge and Research Strategy (2005)

18. Fasoli, T., et al.: Challenges in Data Management in Product Life Cycle Engineering. In: Glocalized Solutions for Sustainability in Manufacturing, pp. 525-530 (2011)

19. Staw, B.M.: Organizational behavior: A review and reformulation of the field's outcome variables. Annual Review of Psychology 35(1), 627-666 (1984)

20. Davis, K., Newstrom, J.W.: Human behavior at work: Organizational behavior (1989)

21. Greenhalgh, C., Rogers, M.: Innovation, intellectual property, and economic growth. Princeton University Press (2009)

22. Udwadia, F.E.: Creativity and innovation in organizations: Two models and managerial implications. Technological Forecasting and Social Change 38(1), 65-80 (1990)

23. Cumming, B.S.: Innovation overview and future challenges. European Journal of Innovation Management 1(1), 21-29 (1998)

24. Jiménez-Jiménez, D., Sanz-Valle, R.: Innovation, organizational learning, and performance. Journal of Business Research (2011)

25. Cooper, J.R.: A multidimensional approach to the adoption of innovation. Management Decision 36(8), 493-502 (1998)

26. Damanpour, F., Walker, R.M., Avellaneda, C.N.: Combinative effects of innovation types and organizational performance: A longitudinal study of service organizations. Journal of Management Studies 46(4), 650-675 (2009)

27. Gumusluoglu, L., Ilsev, A.: Transformational leadership, creativity, and organizational innovation. Journal of Business Research 62(4), 461-473 (2009)

28. Yang, Y.C., Hsu, J.M.: Organizational process alignment, culture and innovation. Afr. J. Bus. Manage. 4(11), 2231-2240 (2010)

29. Hernández-Mogollon, R., et al.: The role of cultural barriers in the relationship between open-mindedness and organizational innovation. Journal of Organizational Change Management 23(4), 360-376 (2010)

30. Kleysen, R.F., Street, C.T.: Toward a multi-dimensional measure of individual innovative behavior. Journal of Intellectual Capital 2(3), 284-296 (2001)

31. Pugh, D.S., et al.: Dimensions of organization structure. Administrative Science Quarterly, 65-105 (1968)

32. Damanpour, F.: Organizational complexity and innovation: developing and testing multiple contingency models. Management Science, 693-716 (1996)

33. Shane, S.: Cultural influences on national rates of innovation* 1 . Journal of Business Venturing 8(1), 59-73 (1993)

34. Weerawardena, J., O'Cass, A., Julian, C.: Does industry matter? Examining the role of industry structure and organizational learning in innovation and brand performance. Journal of Business Research 59(1), 37-45 (2006) 
35. Woodman, R.W., Sawyer, J.E., Griffin, R.W.: Toward a theory of organizational creativity. Academy of Management Review, 293-321 (1993)

36. Crandall, R.E., Crandall, W.R., Chen, C.C.: Principles of supply chain management. CRC Press Taylor \& Francis Group (2010)

37. Ming, X.G., Lu, W.F.: A framework of implementation of collaborative product service in virtual enterprise. In: Innovation in Manufacturing Systems and Technology, IMST (2003)

38. Romer, P.: Idea gaps and object gaps in economic development. Journal of Monetary Economics 32(3), 543-573 (1993)

39. Ameri, F., Dutta, D.: Product lifecycle management: closing the knowledge loops. Computer-Aided Design and Applications 2(5), 577-590 (2005)

40. Serrano, V., Fischer, T.: Collaborative innovation in ubiquitous systems. Journal of Intelligent Manufacturing 18(5), 599-615 (2007)

41. Srinivasan, V.: An integration framework for product lifecycle management. ComputerAided Design (2011)

42. Subrahmanian, E., et al.: Challenges in supporting product design and manufacturing in a networked economy: A PLM perspective. PLM 5, 11-13 (2005)

43. Alegre, J., Chiva, R.: Assessing the impact of organizational learning capability on product innovation performance: An empirical test. Technovation 28(6), 315-326 (2008)

44. Aragon-Correa, J.A., Garcia-Morales, V.J., Cordon-Pozo, E.: Leadership and organizational learning's role on innovation and performance: Lessons from Spain. Industrial Marketing Management 36(3), 349-359 (2007)

45. Read, A.: Determinants of successful organisational innovation: a review of current research. Journal of Management 3(1), 95-119 (2000)

46. Molina Morales, F.X., Martínez Fernández, M.T.: Social networks: effects of social capital on firm innovation. Journal of Small Business Management 48(2), 258-279 (2010)

47. Terzi, S., et al.: Product lifecycle management-from its history to its new role. International Journal of Product Lifecycle Management 4(4), 360-389 (2010) 